\title{
Algunas consideraciones sobre la localización de actividades no deseables: el caso de los residuos urbanos
}

\author{
M. V. Azcárate, C. Muguruza y J.M. Santos
}

\section{RESUMEN: SUMMARY:}

La ubicación de vertederos, como instalaciones destinadas al reciclaje y reutilización de los residuos urbanos, de acuerdo a la nueva normativa europea, constituye, hoy en día, un problema de primera magnitud, que las diversas instancias del poder territorial están considerando a la hora de elaborar políticas respetuosas con la conservación medioambiental. Sin embargo, la falta de criterios (de carácter positivo y negativo) para la selección de emplazamientos, asi como de una metodología precisa en la definición de un modelo de actividades no deseables, está favoreciendo la localización descontrolada de los mismos dentro del territorio municipal
The location of rubbish dumps, as facilities destined to recycle and re-use urban waste in agreement with the new European regulations, is a problem of the first magnitude nowadays which various responsible authorities give consideration to, when drawing up policies which respect environmental conservation. Nevertheless, the lack of criteria (both positive and negative) for selecting locations, as well as the absence of a methodology needed to define a model of undesirable activities, is encouraging a loss of control their localisation in municipal territory.

\section{INTRODUCCION}

El presente trabajo supone un primer paso, el de la definición del marco legal de referencia, en la concreción de una metodología sobre la lo- 
calización de instalaciones "no deseables"; en concreto, la ubicación de los vertederos de residuos urbanos municipales. Hemos podido observar como la mayoría de los proyectos de construcción de dichas instalaciones, aun cumpliendo todos los requisitos legales y técnicos, no incluyen estudios geográficos previos a la hora de elegir un emplazamiento adecuado. Un estudio de esta naturaleza evitaría, sin duda, gran parte de las alegaciones que, en la práctica, se producen en contra de dichos proyectos, al aportar argumentos objetivos a las disputas territoriales por la implantación de actividades consideradas "non gratas". La búsqueda razonada de un lugar idóneo para dichas instalaciones minimizaría lo que algunos han llegado a denominar "hipersensibilidad ante cualquier propuesta de construcción de nuevas infraestructuras en este campo"(Plan Nacional de Residuos Urbanos).

En los estudios sobre la localización de actividades no deseables se deben tener en cuenta aspectos de muy variada índole, que más adelante esbozaremos, y de los cuales existe abundante bibliografía. Sin embargo, un primer paso en el acercamiento a esta problemática particular exige considerar el marco jurídico existente, en el que este tipo de actividades se debe desarrollar. El análisis de la normativa legal nos ha permitido evaluar profundos cambios socioambientales que se manifiestan, tanto en las consecuencias medioambientales que puedan ocasionar este tipo de instalaciones, como en los criterios en cuanto al emplazamiento más deseable.

Esta nueva realidad normativa debe mucho a la reciente incorporación de nuestro país a la Unión Europea. A ella, hay que añadir la creación del estado de las autonomias, que ha supuesto una estructuración territorial de nuevo cuño, que ha añadido el escalón regional en la planificación de las políticas sectoriales. La legislación sobre esta materia en España, como en otras, ha pasado de ser una legislación exclusivamente estatal y aplicada a todo el territorio nacional, a quedar encuadrada dentro del marco legislativo de la Unión Europea, y a desarrollarse dentro del ámbito territorial autonómico.

\section{LA EVOLUCIÓN DE LA SENSIBILIDAD SOCIAL EN EL TRATAMIENTO DE LOS RESIDUOS URBANOS: DEL “VERTIDO A LA VALORIZACIÓN"}

La gestión de los residuos urbanos ha experimentado un importante cambio en los últimos veinte años y hoy en día constituye uno de los pro- 
blemas medioambientales más inmediatos de la sociedad industrial.

Tradicionalmente, desde la época medieval, el vertido y la incineración de las basuras -todavía sigue siéndolo en muchas sociedades- han constituido la forma más generalizada de eliminar los residuos urbanos. La gente se preocupaba de no almacenar basura en su domicilio particular, razón por la cual eran tiradas a la calle, donde se mezclaban con los excrementos de los animales que circulaban por ellas. Por esta razón, no es de extrañar, que esta circunstancia originara las consiguientes plagas y epidemias, que fácilmente eran transmitidas por las moscas, mosquitos y ratas (Solé,C. op.cit.). El aumento de la población urbana obligó a buscar soluciones adecuadas para el vertido de basuras lejos de las ciudades, que evitaran la grave contaminación ambiental que tales métodos producian.

La acumulación de cantidades cada vez más grandes de residuos urbanos, ligados a la sociedad del desperdicio de "usar y tirar", hizo de la búsqueda de un lugar idóneo para ubicar un vertedero, una tarea prioritaria. La localización de vertederos de residuos urbanos al aire libre, muchas veces en la proximidad de las ciudades, ha sido una de las constantes que ha caracterizado a nuestro paisaje urbano. En los países occidentales, la situación descrita se mantuvo con apenas variaciones hasta finales de los pasados años ochenta. La concienciación de la sociedad, que hasta ese momento había considerado el problema de los residuos urbanos molestos y peligrosos, como algo inevitable, ha llevado a un cambio actitud frente al mismo. Antes, el problema se centraba en la dificultad de encontrar un lugar conveniente, donde ubicar los residuos urbanos, mientras que, actualmente, se piensa más en la posibilidad de reutilizarlos o reducirlos. Las Administraciones públicas con competencias en la materia tan sólo se preocupaban por encontrar emplazamientos donde depositar las basuras que tuvieran el menor rechazo social, y no por analizar cómo depositarlas para su reciclaje o eliminación posterior. Se trataba, simplemente, de evitar problemas sanitarios y/o estéticos, sin plantearse mejorar los esfuerzos técnicos y financieros en lo que podríamos denominar una "gestión medioambiental de los residuos urbanos". Se ha pasado asi de la idea de invertir dinero y esfuerzos en algo en desuso, que suponía una actividad cara e improductiva, a una nueva visión, más positiva, que considera los residuos urbanos como algo a controlar y transformar.

No es de extrañar, que la gestión de los residuos urbanos fuera una actividad prácticamente inexistente. En nuestro país, los depósitos o vertederos urbanos estaban considerados como una actividad molesta e in- 
salubre y quedaban sometidos al régimen jurídico establecido en el Reglamento de Actividades Molestas, Insalubres, Nocivas y Peligrosas (RAMINP), aprobado el 30 de Noviembre de 1961, en sintonía con una concepción que suponía que los residuos urbanos son "algo molesto que se debe rechazar a causa de su aspecto, olor, insalubridad y, en algunos casos, toxicidad" (Solé,C. op.cit).

Como consecuencia de la toma de conciencia de la sociedad en materia medioambiental, se han ido impulsando, en el campo de los residuos urbanos, nuevos sistemas técnicos que ponen el énfasis en la gestión integral de los mismos, con el fin de mantener un medioambiente más limpio y menos contaminado, poniendo, así, freno a la sociedad del despilfarro. No es de extrañar, que hayan surgido, en la década de los años noventa, nuevos conceptos: "reutilización", "recuperación", "reciclaje" o "valorización de los residuos", relacionados con el tratamiento dirigido a recuperar parte del valor de los mismos en términos de materia y/o de energía, que incluyen una gestión racional de los residuos urbanos, donde se incide más en la valorización y no en el vertido.

\section{EL CAMBIO LEGAL EN EL TRATAMIENTO DE LOS RESIDUOS URBANOS: DE LA CONSIDERACIÓN DE ACTIVIDAD INSALUBRE A LA GESTIÓN INTEGRAL.}

\subsection{El concepto de residuo}

Resulta de capital importancia determinar cuando una sustancia adquiere la condición de "residuo", en contraposición a otros productos o bienes ordinarios, pues ello va a condicionar su sujeción a una normativa legal más rigurosa. En el marco de la legislación comunitaria, en materia de residuos, la Directiva del Consejo 75/442/CEE estableció que se entendía por residuo "cualquier sustancia u objeto del cual se desprenda o tenga la intención de desprenderse su poseedor en virtud de las disposiciones nacionales en vigor". Esta Directiva fue modificada por otra más reciente (91/156/CEE), que en su artículo primero entiende por residuo "cualquier sustancia u objeto perteneciente a una de las siguientes categorías: productos caducados, materiales vertidos por accidente, materiales contaminados, elementos y sustancias inutilizables, residuos de procesos industriales, etc. y del cual su poseedor se desprenda o del que tenga la intención o la obligación de desprenderse". 
Años más tarde, mediante decisión de la Comisión de 20-12-1993, se estableció una lista de residuos considerados como tales, dando lugar al Catálogo Europeo de Residuos (CER). A pesar de ello, la inclusión de una determinada sustancia en el CER no implica automáticamente que sea un "residuo", ya que además es necesario que se ajuste a la definición de residuo contenida en la citada Directiva.

La transposición de las Directivas a los Estados miembros no ha sido inmediata, aunque la mayoría de ellos han ido adaptando, progesivamente, la normativa comunitaria a la de rango estatal. Asi, en nuestro país, la Ley 10/1998 recoge las Directivas de la política europea en materia de residuos y supone el establecimiento de una norma común aplicable a todo tipo de residuos, excepto las emisiones a la atmósfera, los residuos radiactivos y los vertidos de efluentes líquidos. Ciñéndonos al concepto de residuo urbano, objetivo de este trabajo, dicha ley sustituye la tradicional denominación de Residuo Sólido Urbano (RSU) por la de Residuo Urbano (RU), el cual queda definido en el artículo 3.b., como "los generados en los domicilios particulares, comercios, oficinas y servicios, así como todos aquéllos que no tengan la calificación de peligrosos y que por su naturaleza o composición puedan asimilarse a los producidos en los anteriores lugares o actividades. Tienen también la consideración de residuos urbanos los siguientes: residuos procedentes de la limpieza de vias públicas, zonas verdes, áreas recreativas y playa; animales domésticos muertos, así como muebles enseres y vehículos abandonados; residuos y escombros procedentes de obras menores de construcción y reparación domiciliaria".

El marco de aplicación de la nueva Ley no se encuentra limitado al tratamiento de los residuos como tales, sino que comprende también los aspectos relativos a las fases previas a su producción. Su objetivo es "prevenir la producción de residuos, establecer el régimen jurídico de su producción y gestión y fomentar, por este orden, su reducción, su reutilización, reciclado y otras formas de valorización, asi como regular los suelos contaminados, con la finalidad de proteger el medio ambiente y la salud de las personas" (artículo 1).

Además, dicha Ley establece en su artículo 5, que la Administración General del Estado elaborará diferentes Planes Nacionales de Residuos, mediante la integración de los respectivos Planes Autonómicos. En este sentido, el recientemente aprobado Plan Nacional 
de Residuos Urbanos (2000-2006) queda encuadrado dentro del marco normativo vigente, tanto nacional como comunitario, dando respuesta a la obligación de establecer planes de residuos, tal y como se especifica en la Directiva 91/156/CEE, a que hemos hecho referencia, conocida como directiva marco de residuos, ajustándose también a las exigencias de la Directiva del Consejo 1999/31/CEE, relativa al vertido de residuos.

Cuadro I. Composición media de los RU en España (1991-1996)

\begin{tabular}{lcc}
\hline Componente & $\begin{array}{c}\text { Composición media } \\
(1991-1996)(\%)\end{array}$ & $\begin{array}{c}\text { Generación 1996 } \\
(\text { Tm/año })\end{array}$ \\
\hline Materia Orgánica & 44,06 & 7.567 .387 \\
Papel - Cartón & 21,18 & 3.637 .704 \\
Plástico & 10,59 & 1.818 .852 \\
Vidrio & 6,93 & 1.190 .240 \\
Materiales férricos & 3,43 & 589.109 \\
Materiales no férricos & 0,68 & 116.791 \\
Maderas & 0,96 & 164.882 \\
Otros & 12,17 & 2.090 .220 \\
Totales & 100,0 & 17.175 .186 \\
\hline
\end{tabular}

Fuente: Plan Nacional de Residuos Urbanos (2000-2006)

Los residuos urbanos se suelen clasificar en tres grandes grupos: los inertes, que agrupan la chatarra, el vidrio, la cerámica y los escombros; los combustibles, que contienen el papel, el cartón, el plástico, los textiles, la madera, la espuma y los cueros; y los orgánicos que son todos aquéllos residuos sólidos urbanos putrescibles y con posibilidad de fermentación. En España, presentan una composición tipo en la que aproximadamente la mitad, en peso, corresponde a materia orgánica, siguiendo en importancia el papel-cartón, el plástico, el vidrio y los metales (Cuadro I).

La composición de los residuos urbanos es muy heterogénea, variando en función del país, zona urbana o rural, nivel de vida, hábitos de consumo, estación del año, etc. En el Cuadro II, se puede apreciar el peso relativo de las diferentes comunidades autónomas en la generación de residuos urbanos, así como su intensidad, medida en Kilogramos por habitante y día. 
Algunas consideraciones sobre la localización de actividades no deseables...

Cuadro II. Generación de residuos urbanos en España (1996)

\begin{tabular}{|c|c|c|c|c|}
\hline \multirow[t]{2}{*}{ Comunidad autónoma } & \multirow{2}{*}{$\begin{array}{c}\text { Población } \\
\text { (Padrón 1996) }\end{array}$} & \multicolumn{2}{|c|}{ Generación } & \multirow{2}{*}{$\begin{array}{c}\text { Coef. de generación } \\
\qquad(\mathrm{Kg} / \mathrm{hab} / \mathrm{dia})\end{array}$} \\
\hline & & (Tm/año) & $\%$ & \\
\hline Andalucía & 7.234 .873 & 2.984 .605 & 17,38 & 1,13 \\
\hline Aragón & 1.187 .546 & 416.419 & 2,42 & 0,96 \\
\hline Asturias & 1.087 .885 & 401.419 & 2,34 & 1,01 \\
\hline Baleares & 760.379 & 559.500 & 3,26 & 2,02 \\
\hline Canarias & 1.606 .534 & 966.516 & 5,63 & 1,65 \\
\hline Cantabria & 527.437 & 194.875 & 1,13 & 1,01 \\
\hline Castilla-La Mancha & 1.712 .529 & 673.581 & 3,92 & 1,08 \\
\hline Castilla y León & 2.508 .496 & 1.029 .036 & 5,99 & 1,12 \\
\hline Cataluña & 6.090 .040 & 2.833 .061 & 16,50 & 1,27 \\
\hline Extremadura & 1.070 .244 & 412.631 & 2,40 & 1,06 \\
\hline Galicia & 2.742 .622 & 810.275 & 4,72 & 0,81 \\
\hline Madrid & 5.022 .289 & 2.012 .000 & 11,71 & 1,10 \\
\hline Murcia & 1.097 .249 & 394.494 & 2,30 & 0,99 \\
\hline Navarra & 520.574 & 207.261 & 1,21 & 1,09 \\
\hline País Vasco & 2.098 .055 & 1.063 .549 & 6,19 & 1,39 \\
\hline La Rioja & 264.941 & 103.121 & 0,60 & 1,07 \\
\hline Comunidad Valenciana & 4.009 .329 & 2.048 .377 & 11,93 & 1,40 \\
\hline Ceuta & 68.796 & 32.000 & 0,19 & 1,27 \\
\hline Melilla & 59.576 & 32.850 & 0,19 & 1,51 \\
\hline Totales & 39.669 .394 & 17.175 .186 & 100,0 & 1,21 \\
\hline
\end{tabular}

3.2. La política ambiental en materia de residuos urbanos.

Como ya hemos comentado, España es un país de larga tradición en vertidos como elemento básico en la gestión de sus basuras. Por toda la geografía española se reparten gran cantidad de vertederos, en su mayoría incontrolados. En el comienzo de los años ochenta, se inició un proceso en el que muchos Ayuntamientos españoles reconvirtieron estos vertederos incontrolados en controlados, aunque según datos del Ministerio de Medio Ambiente, recogidos en su Memoria Anual, de los 8.000 municipios existentes en España, poco más de la mitad disponian de vertederos controlados, y aún así, la mayoría de ellos carecía de impermeabilización, por lo que los lixiviados contaminan las aguas superficiales y subterráneas y el suelo, al mismo tiempo que el gas metano que emiten favorece el efecto invernadero (Cuadro III). Por este motivo, en la década de los noventa, nuestro arcaico modelo de gestión de RU, basada en el vertido, se hace ya insostenible. 
Cuadro III. Tratamiento de los RU. Destino final (1996)

\begin{tabular}{lcc}
\hline Sistema & $\begin{array}{c}R U \text { tratados } \\
(T m / a \tilde{n} o)\end{array}$ & $\begin{array}{c}R U \text { tratados } \\
(\%)\end{array}$ \\
\hline Vertido autorizado & 9.989 .386 & 58,2 \\
Vertido Incontrolado & 2.101 .250 & 12,2 \\
Reciclaje & 1.985 .040 & 11,6 \\
Compostaje & 2.394 .162 & 13,9 \\
Incineración (con recuperación de energia) & 627.949 & 3,7 \\
Incineración (sin recuperación de energía) & 77.399 & 0,5 \\
Totales & 17.175 .186 & 100,0 \\
\hline
\end{tabular}

Fuente. Plan Nacional de Residuos Urbanos (2000-2006)

La organización territorial del Estado de las Autonomías resulta clave en la tarea de establecer la normativa de regulación de los RU. La Constitución española de 1978 determina el régimen de distribución territorial de competencias sobre la gestión y tratamiento de los mismos. Así, la política ambiental española en materia de residuos supone un reparto competencial tripartito entre la administración estatal, la autonómica y la local El cuadro IV recoge las principales tareas, relativas a la preparación y definición de la política ambiental, legislación y ejecución, así como los instrumentos operacionales para acometer tales políticas.

Cuadro IV. Organización territorial española de la política ambiental, en materia de residuos urbanos

\begin{tabular}{|c|c|c|c|}
\hline Organización & Tareas principales & \multicolumn{2}{|c|}{ Instrumentos } \\
\hline \multirow{7}{*}{$\begin{array}{l}\text { Ministerio de } \\
\text { Medio Ambiente }\end{array}$} & - Coordinación y diseño & \multirow{4}{*}{\multicolumn{2}{|c|}{$\begin{array}{l}\text { - Planes Nacionales } \\
\text { - Comisión Nacional de } \\
\text { Coordinación de la } \\
\text { Política Ambiental }\end{array}$}} \\
\hline & de la política ambiental & & \\
\hline & & & \\
\hline & & & \\
\hline & \multirow[t]{3}{*}{ - Legislación } & - Ley 10/98 & - Ley 11/97 \\
\hline & & - RAMINP & - Ley 38/72 \\
\hline & & - Ley 29/85 & - Ley $22 / 88$ \\
\hline \multirow[t]{2}{*}{ CC.AA. } & $\begin{array}{l}\text { - Preparación y definición } \\
\text { de la política }\end{array}$ & \multicolumn{2}{|c|}{$\begin{array}{l}\text { - Planes Regionales } \\
\text { de Gestión }\end{array}$} \\
\hline & - Legislación & \multicolumn{2}{|c|}{$\begin{array}{l}\text { - Leyes y decretos } \\
\text { autonómicos }\end{array}$} \\
\hline
\end{tabular}




$\begin{array}{lll}\text { Ayuntamiento } & \text { - Preparación y definición } & \text { - Plan de urbanismo } \\ & \text { de la política } & \\ & \text { - Legislación } & \text { - Ordenanzas Municipales } \\ & \text { - Ejecución } & \text { - Recogida de R.S.U. }\end{array}$

Fuente: Guia de Vertederos. Op.cit. pág.1

La Ley 10/98 establece la facultad del gobierno estatal para la definición, mediante un plan de ámbito nacional, de los principios generales orientadores de la política ambiental en materia de RU. Asímismo, en su artículo 4, establece que "corresponderá a las CCAA la elaboración de planes autonómicos de residuos" y que "las entidades locales serán competentes para la gestión de residuos urbanos, en los términos establecidos en esta ley y en las que, en su caso dicten las Comunidades Autónomas. Corresponde a los municipios, como servicio obligatorio, la recogida, el transporte $y$, al menos, la eliminación de los residuos urbanos, en la forma en que establezcan las respectivas Ordenanzas".

En este sentido, el recientemente aprobado Plan Nacional de Residuos Urbanos (PNRU) (2000-2006) queda encuadrado dentro del marco normativo vigente, tanto nacional como comunitario, dando respuesta a la obligación de establecer planes de residuos, tal y como se especifica en la mencionada ley 10/98, así como en la directivas 91/156/CEE y 1999/31/CEE, que tuvimos ocasión de comentar con anterioridad. La entrada en vigor de esta última condena el habitual sistema de gestión realizado en España. La reducción en los volúmenes de los residuos y la obligación de sólo llevar a vertederos los residuos previamente tratados, modificará sustancialmente la situación actual. La inmensa mayoría de nuestros vertederos deberán ser clausurados, a la vez que se abrirán nuevas instalaciones que cumplan con los requisitos de la mencionada Directiva.

El desarrollo del PNRU hasta el año 2006 está conformado por una serie de Programas Nacionales en los que se especifican claramente los objetivos, las actuaciones previstas y la evaluación económica que supondrá la puesta en marcha de cada uno de ellos, en el marco de los principales líneas de actuación que inspiran el PNRU. Así, el Programa Nacional de Eliminación contempla los siguientes objetivos:

- Eliminación ambientalmente correcta en vertederos controlados de rechazos de aquellos residuos que, por distintas razones, no pueden 
ser recuperados o valorizados por otros métodos contemplados en este Plan, aplicando para ello las tecnologías menos contaminantes.

- Eliminación del vertido incontrolado al final del año 2006, con el objetivo intermedio de que al final del año 2001 sólo el $5 \%$ de los RU se depositen de forma incontrolada.

- En el mismo año 2006, todos los vertederos en uso serán verdaderamente controlados, entendiendo por este término el cumplimiento de lo exigido por la nueva Directiva de Vertido 99/31/CE. La eliminación por vertido será del $33,1 \%$ del total de RU.

- En los casos en los que ello sea técnicamente posible, adaptación de los vertederos existentes a la Directiva sobre Vertido.

- Eliminación y aprovechamiento del biogás de grandes vertederos para la obtención de energía eléctrica.

- Elaboración de una norma técnica para la construcción de vertederos.

- Sellado y recuperación de todas las zonas degradadas por vertidos incontrolados antes del final del periodo de vigencia del PNRU".

Para cumplir estos objetivos se clausurarán y sellarán cerca de 4.000 vertederos incontrolados, restaurando el entorno y el medio natural, se construirán 126 nuevas Estaciones de Transferencia, y se adaptarán 30 vertederos así como se construirán unos 150 vertederos controlados, de acuerdo con lo dispuesto en la citada Directiva sobre Vertidos.

\section{LA EVOLUCIÓN DE LA NORMATIVA EN MATERIA DE UBICACIÓN DE VERTEDEROS}

En el caso español, han sido y siguen siendo, el vertido y el vertedero, la solución más extendida al problema de los residuos urbanos. "En el caso de los residuos domésticos, durante muchos años, han existido cientos de instalaciones incontroladas, donde pequeñas y medianas poblaciones hacian el vertido de sus residuos. En el comienzo de los años ochenta, se inició un proceso por el que muchos ayuntamientos españoles reconvirtieron estos vertederos incontrolados en vertederos sanitariamente controlados, sin otra adaptación que su propio reconocimiento legal. Es decir, aquellos sitios donde de una manera más o menos conocida y tolerada por las autoridades se venían depositando los residuos, con un simple procedimiento administrativo, se convertían en lugares autorizados" (Martínez Ordago,C. op.cit.). Para admitir esta situación se ar- 
gumentaba que en España había mucho suelo y que era una forma barata de solucionar el problema, sin preocuparse por los daños medioambientales y sanitarios.

En la práctica, los vertederos se instalaban sin ningún estudio previo, ni de carácter geológico, ni morfológico, ni topográfico, ni hidrológico. La legislación no obligaba a ello. Como hemos señalado en otro apartado, los vertederos eran clasificados como actividades molestas, insalubres y nocivas -no peligrosas- (RAMINP). La expedición de la licencia de construcción era competencia de los alcaldes de los municipios. Su emplazamiento debía supeditarse a lo dispuesto en las Ordenanzas Municipales y Planes de Urbanismo, y, en todo caso, las actividades insalubres sólo podían emplazarse, según el citado reglamento, a 2.000 metros a contar del núcleo más próximo de población agrupada. No existía ninguna referencia a otro factor de localización que no fuese la distancia a los núcleos de población. No había ningún criterio medioambiental, reflejando, esta circunstancia, la escasa preocupación por las consecuencias que sobre el medio pudieran tener este tipo de instalaciones.

La concienciación social acerca de los problemas medioambientales, surgida en los últimos veinte años, ha tenido su respuesta en un cambio de actitud hacia el problema de los residuos urbanos, poniendo el énfasis en una gestión medioambiental integral. Todo ello ha sido plasmado en la legislación, habiéndose llevado a cabo importantes modificaciones que definen un nuevo marco de acción. La Unión Europea marca la línea a seguir. La elaboración de un Plan Nacional de Residuos Urbanos y la necesaria transposición a la normativa española de la directiva de vertidos, han diseñado un escenario absolutamente diferente para los vertederos españoles.

En cuanto a la ubicación, la Directiva comunitaria hace referencia a este tema en el Anexo I, y en los siguientes términos:

"Para la ubicación de un vertedero deberán tomarse en consideración los siguientes requisitos:

a) Las distancias entre el límite del vertedero y las zonas residenciales y recreativas, vias fluviales, masas de agua y zonas agrícolas o o urbanas.

b) La existencia de aguas subterráneas, aguas costeras o reservas naturales de la zona.

c) Las condiciones geológicas o hidrológicas del área. 
d) El riesgo de inundaciones, hundimientos, corrimientos de tierra o aludes en el emplazamiento del vertedero.

e) La protección del patrimonio natural o cultural de la zona."

Así, el vertedero sólo podrá autorizarse si las características del emplazamiento con respecto a los requisitos mencionados indican que el vertedero no plantea ningún riesgo grave para el medioambiente.

Estos criterios no se traducen en normas restrictivas precisas, que detallen los criterios de forma rigurosa y exacta1. Por ello, no es de extrañar, que no se haga referencia a las distancias mínimas con respecto a los núcleos habitados (único criterio que se establecía en el RAMINP en consonancia con su concepción del vertedero como actividad molesta e insalubre), y sí a otras circunstancias medioambientales, decisivas en la elaboración de un modelo de localización de vertederos de Residuos Urbanos con criterios de protección del medio, con vistas a que el emplazamiento suponga el menor perjuicio para el medioambiente tanto natural, como social y cultural de la zona.

\section{LA SELECCIÓN DEL EMPLAZAMIENTO}

En cuanto a los procedimientos para la selección de emplazamientos de este tipo de actividades, se debería actuar de acuerdo con los Planes de Urbanismo y las Ordenanzas Municipales de los respectivos Ayuntamientos. En el caso de no existir dichas normas, será la Comunidad Autónoma quien determine el lugar adecuado para su instalación. Sin embargo, desde el punto de vista de la planificación territorial, a nivel regional, como ya venimos señalando, no existe ninguna metodología clara y precisa para determinar la selección del emplazamiento más adecuado a la instalación de una actividad de esta naturaleza. Cabría resaltar, además, la falta de conexión y coordinación existente entre los diferentes escalones de las políticas sectoriales, desde el ámbito comunitario (Directiva de Vertidos) hasta el ámbito nacional (Plan Nacional de Residuos Urbanos), autonómico (Planes Regionales de Gestión) o municipales (Ordenanzas Municipales y Planes de Urbanismo).

Sólo hemos encontrado en la normativa comunitaria una referencia a distancias mínimas, en la enmienda que figura en la propuesta reexaminada de la Directiva del Consejo relativa ał vertido de residuos. En concreto, "la Comisión hace suya la enmienda 18, que vuelve a recoger una distancia mínima indicativa. Quedó aceptado el siguiente texto: «las distancias entre el límite del vertedero y las zonas residenciales y recreativas, vias fluviales, masas de agua y otras zonas agrícolas o urbanas, utilizaran con carácter indicativo, una separación mínima de 0,5 $\mathrm{Km}$, en el caso de vertederos municipales". 
Debido a la consideración de los vertederos como una actividad molesta, los ayuntamientos, condicionados por una clara presión social, suelen evitar su emplazamiento dentro del municipio, en lo que viene denominándose efecto NIMBY (Not In My Back Yard: no en mi jardín trasero). La Ley 10/98 establece que corresponden a las CCAA formular planes de gestión de residuos en su ámbito territorial. Sin embargo, la falta de criterios decisivos para la selección de emplazamientos, así como de una metodología precisa y única en la elaboración de un modelo de localización de actividades "no deseables", favorece la ubicación descontrolada en cualquier lugar del municipio, cuando tal instalación debe llevarse acabo dentro del territorio municipal.

La determinación de unos criterios que nos sirvan para la ubicación de un vertedero Residuos Urbanos se debe realizar de forma escalonada. Primeramente, se deben establecer los criterios limitantes que supongan restricciones absolutas, para, a continuación, definir los factores que caracterizan el territorio en función de la aptitud para el establecimiento de esta actividad, finalizando por la cuantificación separada y posteriormente integrada de los mismos, con la finalidad de evaluar la idoneidad de la propuesta.

Los criterios excluyentes (aquellas áreas en las que es inaceptable la ubicación de un vertedero) deben venir determinados por la normativa y los impedimentos técnicos. Las áreas en las que no está permitido establecer un vertedero son los núcleos urbanos, las zonas residenciales, los parques naturales, los cementerios, las zonas cercanas a los aeropuertos, por la posible atracción de las aves, etc., lugares donde la ubicación de instalaciones de este tipo producirían graves problemas de deterioro medioambiental.

El siguiente paso está dirigido a caracterizar dicho territorio en función de su adecuación, elaborando una serie de criterios de idoneidad positiva y negativa. Los criterios de idoneidad positiva incluyen:

- La proximidad a una vía de comunicación que permita a los camiones de recogida de basuras la accesibilidad al lugar.

- La cercanía a los núcleos habitados. El lugar no deberá estar muy alejado de las zonas de recogida de las basuras para limitar las distancias en el transporte.

- La disponibilidad, en las proximidades, de tierra o materiales que deben servir de cobertura. 
Los criterios de idoneidad negativa se refieren a zonas donde en principio no se debería buscar el emplazamiento, aunque no se excluyan "a priori". La exclusión de estas zonas depende de la situación local. Así se tendrán en cuenta:

- Las características edafológicas: el suelo deberá ser lo menos permeable posible.

- Las características hidrológicas:

- El vertedero se situará a bastante distancia de las corrientes de agua y de los puntos de captación de agua utilizada para el consumo humano.

- Se tendrá en cuenta la presencia de aguas subterráneas, acuíferos y el nivel freático.

Una vez seleccionadas una serie de áreas, en las que se pueda ubicar el vertedero, siguiendo los criterios y factores anteriormente expuestos, se pasará a valorar y comparar dichas áreas. Ello se debe realizar utilizando una serie de parámetros medioambientales:

- El vertedero se situará lo más alejado posible de playas, campings, balnearios, viviendas asiladas, evitando las molestias ocasionadas por el olor, el polvo, los transportes.

- Se situará lejos de paisajes de alto valor ecológico, bosques, parajes que constituyen parte del patrimonio cultural y natural del municipio.

- Se valorará también la propiedad del terreno, es decir, el costo que pueda suponer la compra del mismo (propiedad privada o municipal), y el costo de su preparación previa.

Como vemos, existen pocos criterios tan precisos que no ofrezcan lugar a dudas (salvo los incluidos en la Ley y en los requerimientos técnicos). A pesar de que en el futuro se verterá una menor cantidad de residuos y sólo se depositarán en vertederos aquéllos que hayan sido previamente tratados, se construiran nuevas instalaciones y por tanto seguirá exisitiendo la necesidad de buscar emplazamientos adecuados. Por ello, y para minimizar el riesgo ambiental de este tipo de instalaciones, es importante diseñar un modelo de localización tras un estudio riguroso de las características geográficas, geológicas, paisajísticas, hidrológicas, etc. del término municipal donde se vaya a instalar un vertedero de residuos urbanos. 


\section{BIBLIOGRAFIA}

FERNÁNDEZ RAMOS. S. (1996): EI marco jurídico comunitario en materia de residuos. Noticias de la Unión Europea. CISS.

FUNDACIÓN GENERAL DE LA U.C.M. (1998): Tratamiento y gestión de residuos. Cursos de Verano. Agosto 1997. San Lorenzo de El Escorial.

GRUPO EP (ed.) (1999): Guía de vertederos. Grupo Lara.

MARTINEZ ORGADO, C. (1998): Los vertederos en España. Club Español de los Residuos. Boletín de Debate.

MINISTERIO DE MEDIO AMBIENTE (1998): Memoria anual.

PARPAL MARFÁ, J. (1998): Los vertederos de R.S.U. ¿Solución o equivocación?. Club Español de los Residuos. Boletín de Debate.

RIAZA, M.A. (1998): Presente y futuro del vertido y los vertederos. Club Español de los Residuos. Boletín de Debate.

SOLÉ, C. (dir.) (1998): Medio ambiente. Prevención y control de residuos sólidos urbanos. Fundación BBV,

TINAS GÁLVEZ, J. (1998): Presente y futuro del vertido y los vertederos. Club Español de los Residuos. Boletín de Debate.

\section{LEGISLACIÓN CONSULTADA}

Reglamento de Actividades Molestas, Insalubres, Nocivas y Peligrosas (RAMINP), de 30 de Noviembre de 1961.

Ley de Envases y Residuos de Envases, de 24 de abril de 1997.

Ley de Residuos, de 21 de Abril de 1998.

Propuesta reexaminada de Directiva del Consejo relativa al Vertido de Residuos, de 26 de marzo de 1999.

Directiva del Consejo 1999/31/CEE relativa al Vertido de Residuos, de 26 de abril de 1999.

Plan Nacional del Residuos Urbanos (2000-2006), de 5 de enero de 2000. 